\title{
Choroidal metastasis as the first sign of bronchioloalveolar lung cancer: case report
}

\section{Metástase coroidal como primeira manifestação de carcinoma bronquioloalveolar: relato de caso}

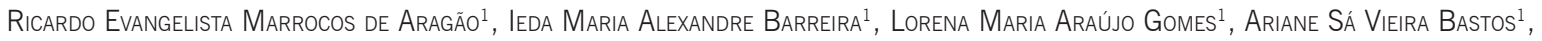
FELIPE DE FREITAS BESERRA ${ }^{1}$

\begin{abstract}
Metastatic tumors are the most common intraocular malignances and choroid is by far the most common site. Breast and lung cancer are the first cause in women and men respectively. We report the case of a 71-year old woman who had choroidal tumor in her left eye. Further image body scans demonstrated several lesions in both sides of the lungs with dissemination to other organs. Diagnosis of a brochioloalveolar carcinoma established after a biopsy carried out. The patient died before initiating a proper treatment.
\end{abstract}

Keywords: Choroid; Neoplasm metastasis; Eye neoplasms; Lung neoplasm; Eye/ pathology; Case report

\section{RESUMO}

Tumor metastático é a neoplasia ocular mais frequente, e a coroide é o local mais comum desta. Tumor de mama seguido de tumor pulmonar são as causas mais comuns demetástases oculares em mulheres e homens, respectivamente. Relatamos o caso de uma paciente de 71 anos com tumor coroidal no ol ho esquerdo. Posteriormente, estudos de imagem mostraram lesões pulmonares em ambos os pulmôes e disseminação a outros órgãos. O diagnóstico de carcinoma bronquioloalveolar foi feito por biópsia. A paciente foi a óbito antes de se iniciar tratamento adequado.

Descritores: Coróide;Metástaseneoplásica; Neoplasia ocular; Neoplasias pulmonares; Olho/patologia; Relato de caso

\section{INTRODUCTION}

The incidence of ocular metastasis from lung cancer is reported to be $2-7 \%$ according to the international literature. The majority of cases involves end-stage patients ${ }^{(1)}$. Metastatic tumors are the most common intraocular malignancies, and choroid is by far the most common site for intraocular malignancies. Multiple foci are usually involved and bilateral involvement is frequently seen ${ }^{(2)}$. The lung cancer is the first cause of choroidal metastasis in men, as the breast cancer is in women. Estimates of the incidence of intraocular metastases in patients dying from disseminated cancer range from 22,000 to 66,000 affected individuals per year in the United States ${ }^{(3)}$.

\section{CASE PRESENTATION}

A 71 year-old woman noticed, progressive vision reduction in both eyes. Ocular examination revealed her best visual acuity to be 20/40 RE (right eye) and 20/100 LE (left eye). Results of her slit lamp revealed nuclear cataract in both eyes. Her pupil size and reaction was normal. Her ocular movements were normal in all gazes. Her intraocular pressure was also normal. Fundus examination of the left eye showed an ill-defined, yellow-white elevated lesion in choroid about five times the disc diameter in size (Figure 1). A fundus picture of the right eye was normal. An ultrasonographic evaluation of the eye demonstrated that the tumor had a height 4,1 mm, anterior-posterior length $13 \mathrm{~mm}$ and lateral length $12,9 \mathrm{~mm}$. The tumor revealed a dome-surfaced, elevated choroidal lesion with moderated internal reflectivity. Fluorescein angiography showed hiperfluorescence from the surface of her choroidal tumor. The lesion was on its late phase and it had already accumulated subretinal fluid. Routine systemic investigation including complete blood cell count, platelet count, bleeding time, urine analysis, serum electrolytes, blood biochemical studies for hepatic and renal function was carried out A chest $x$-ray showed a homogenous opaque mass in patient's left hilar area. A computer tomography scan of the thorax revealed a several small nodules in both superior lobe of the lung and pleural effusions. (Figure 2). Transbronchial biopsy revealed bronchioloalveolar carcinoma (Figure 3). At this time the patient also showed bone metastasis. The chemotherapy was not initiated because our patient died after few weeks.

\section{DISCUSSION}

The highly vascular uveal tract is the most common part of the eye involved by metastasis. Within the uvea, the choroid (88\%) is the most commonly affected site followed by the iris (9\%) and ciliary body (2\%). Breast cancer seems to be the most frequent type of cancer giving intraocular metastasis ${ }^{(4)}$.

The incidence for breast cancer is reported to be $37-41 \%$, while lung cancer is considered to be responsible for no more than $7 \%$ of choroidal metastasis. Approximately $50 \%$ of suspect choroidal metastasis and no history of cancer, has no primary site detected despite systemic evaluation by oncologists. It is generally considered that this kind of metastatic lesion occur at the final stages of the disease, where the mean survival is not expected to be more than 6 months and the majority of the patients already suffer from the typical lung cancer symptoms. The reason for this unusual site to be target for secondary metastasis from lung cancer is generally unknown. It is, however speculated that is high vascularity may consist a reasonable
Submitted for publication: October 4, 2012

Accepted for publication: June 20, 2013

Study carried out at Universidade Federal do Ceará - UFC, Fortaleza (CE), Brazil.

Physician, Ophthalmology Service, Hospital Universitáro Walter Cantídio, Universidade Federal do Ceará - UFC, Fortaleza (CE), Brazil.
Funding: No specific financial support was available for this study.

Disclosure of potential conflicts of interest: R.E.M.de Aragão, None; I.M.A.Barreira, None L.M.A.Gomes, None; A.S.V.Bastos, None; F.F.Beserra, None.

Endereço para correspondência: Ricardo Evangelista Marrocos de Aragão. Rua Osvaldo Cruz, 2335 - Fortaleza (CE) -60125-151 - Brazil - E-mail: ricardomarrocos@yahoo.com 


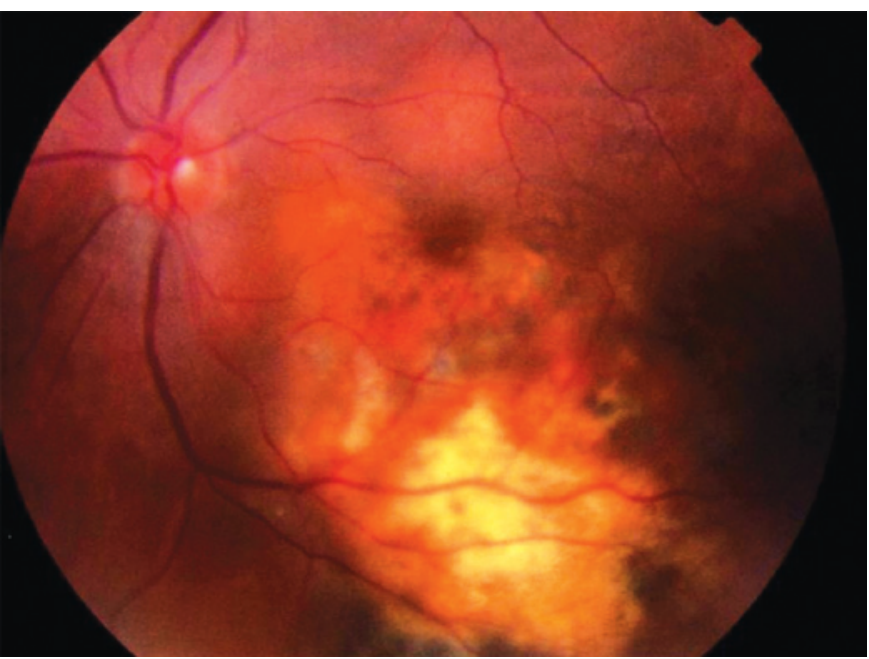

Figure 1. Fundus photography of the left eye showing the choroidal metastasis.

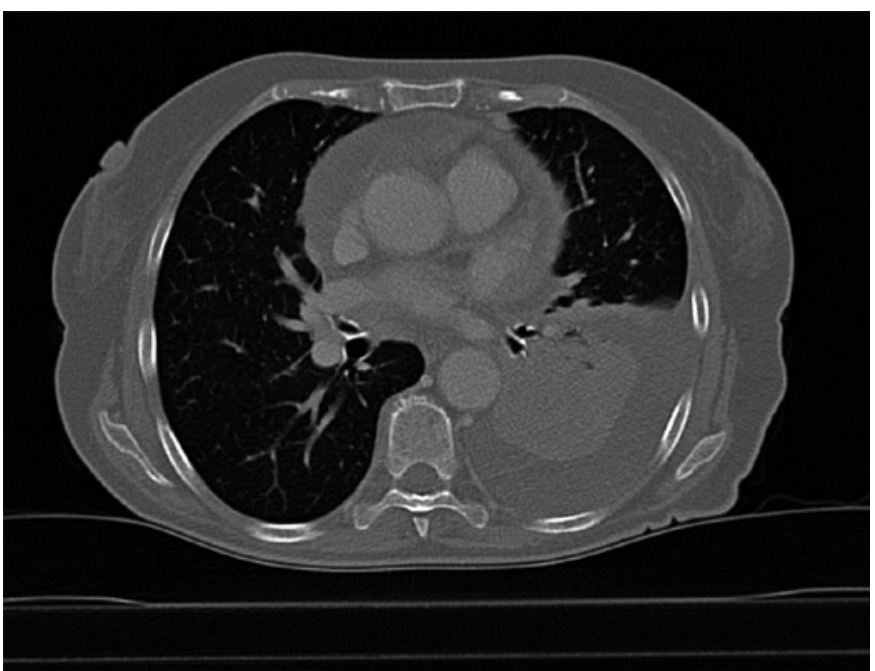

Figure 2. Computer tomography features of the lesions in the lung showing small nodules and pleural effusion.

explanation (1). The other frequent sites of choroidal metastasis are alimentary tract cancers, prostate, skin melanoma, kidneys, contralateral choroidal melanoma, thyroid and testis ${ }^{(5)}$

To date, only 2 series describing 13 and 90 patients, respectively, with predominantly choroidal metastasis from lung cancer, have been published. Shields and et al. reported that in 56\% of patients with intraocular lung cancer metastasis, the primary tumor was detected after the diagnosis of intraocular metastasis( ${ }^{(6)}$.

Choroidal metastasis commonly complain of loss of vision, pain and photopsia. Ophthalmic examination may reveal multiple or bilateral lesions sometimes associated with exudative retinal detachment. The typical lesion is flat and ill defined, most of the cases grey-yellow or yellow-white, with alterations of the retinal pigment epithelium. In rare cases the breaking of the Bruch membrane can lead to mushroom configuration.

The diagnosis of ocular metastasis is based primarily on clinical findings supplemented by imaging studies. The diagnostic procedures include ultrasonography, fluorescein angiography, computed tomography/MRl, fine needle aspiration, or wedge biopsy. Brain imaging is useful before initiation of radiotherapy to assist in treatment

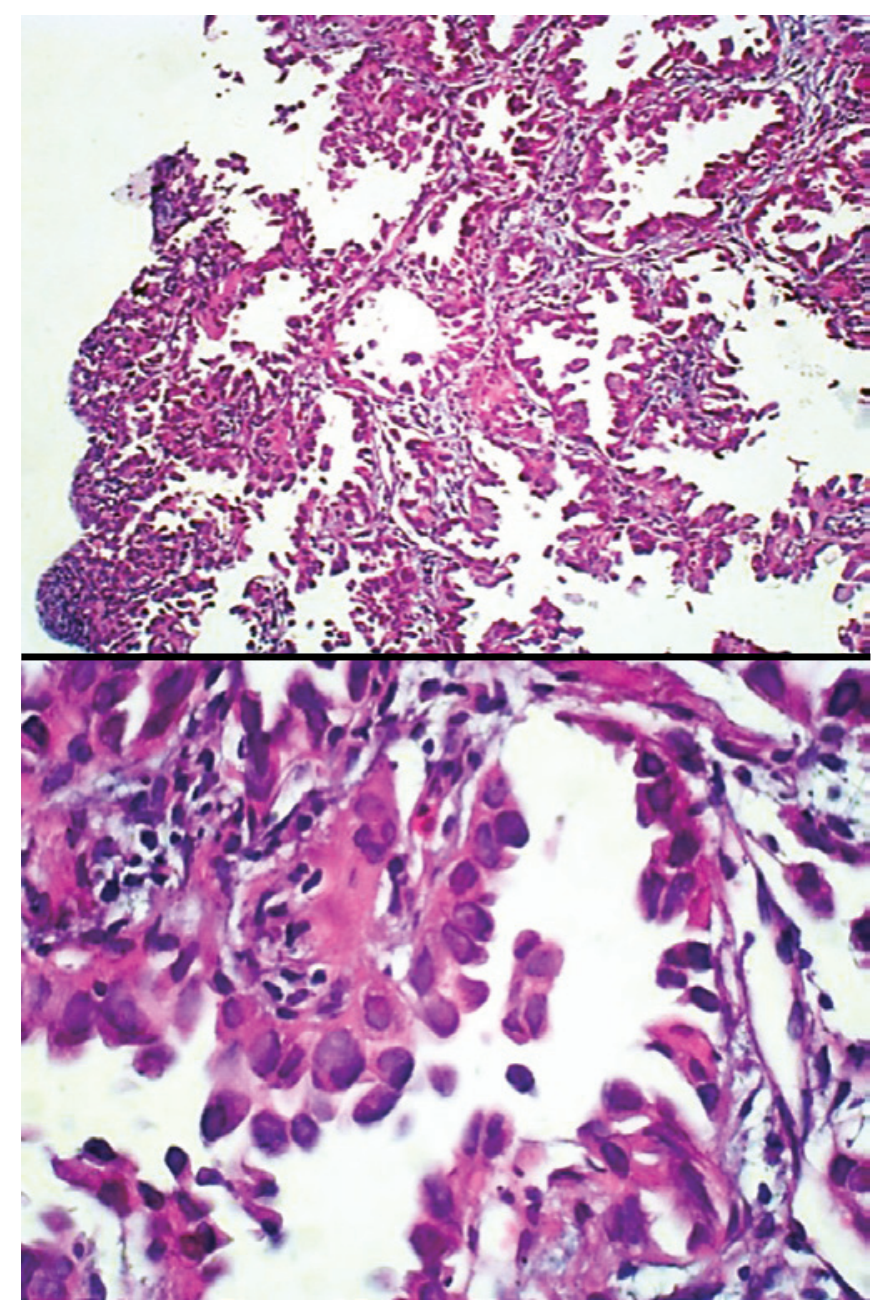

Figure 3. Histopathology images demonstrating brochioloalveolar carcinoma. Showing microscopically the bronchiocarcinoma, composed of columnar cells that proliferated along the framework of alveolar septae. The cells are well-differentiated. All images stained with hematoxylin-eosin.

planning. It is reported that $22 \%$ of patients diagnosed with CM had a concurrent diagnosis of central nervous system metastasis. Differential diagnosis includes primary choroidal melanomas, benign lesions such as hemangioma, and inflammatory granulomas ${ }^{(1)}$

Systemic chemotherapy can lead to total involution of the CM with improvement of the visual acuity ${ }^{(7)}$. Despite systemic chemotherapy or hormone therapy the growing of the choroidal metastasis with symptomatic subretinal fluid, external beam radiation therapy or plaque raditoin therapy is recommended. A systematic search for lung cancer is required in patients presenting as CM. If compatible with the patient general status, histologically adapted chemotherapy must be instituted. This approach can avoid the use of radiotherapy and therefore deterioration of the visual acuity after radiation. However, the diagnosis of $C M$ is associated with a poor prognosis. The initial sign of lung cancer may rarely be visual symptoms due to choroidal metastasis. In such a condition, the lung cancer is already at an advanced stage ${ }^{(8)}$.

The ophthalmologist ought to be aware of the choroidal metastasis sings to its prompt recognition and appropriated treatment.

\section{ACKNOWLEDMENT}

The authors thank Dr. Patty Saldanha (pathologist) and Dr. Diana Bezerra (radiologist) for their assistance and appropriate counseling. 
The authors also thank the ICC (Instituto do Cancer do Ceará) for technical assistance.

\section{REFERENCES}

1. Asteriou C, Konstantinou D, Kleontas A, Paliouras D, Samanidis G, Papadopoulou F, et al. Blurred vision due to choroidal metastasis as the first manifestation of lung cancer: a case report. World J Surg Oncol. 2010;8:2.

2. Singh A, Singh P, Sahni K, Shukla V, Pant NK. Non-small cell lung cancer presenting with choroidal metastasis as first sign and showing good response to chemotherapy alone: case report. J Med Case Rep. 2010;4:185.

3. Kreusel KM, Wiegel T, Stange M, Bornfeld N, Hinkelbein W, Foerster MH. Choroidal metastasis in disseminated lung cancer: frequency and risk factors. Am J Ophthalmol. 2002;134(3):445-7.

4. Shields CL, Shields JA, Gross NE, Schwartz GP, Lally SE. Survey of 520 eyes with uveal metastases. Ophthalmology. 1997;104(8):1265-76.

5. Tazi N, Le Thi Huong D, Bodaghi B, Rixe O, Lehoang P, Piette JC. Choroidal metastasis revealing pulmonary adenocarcinoma. Rev Med Interne. 2006;27(9):699-701.

6. Kreusel KM, Bechrakis NE, Wiegel T, Krause L, Foerster MH. Incidence and clinical characteristics of symptomatic choroidal metastasis from lung cancer. Acta Ophtalmolol. 2008;86(5):515-9.

7. Fernandes BF, Fernandes LH, Burnier MN Jr. Choroidal mass as the presenting sign of small cell lung carcinoma. Can J Ophthalmol. 2006;41(5):605-8.

8. Herrag M, Lahmiti S, Yazidi AA, Le Lez ML, Diot P. Choroidal metastasis revealing a lung adenocarcinoma. Ann Thorac Surg. 2010;89(3):1013-4. 